\title{
Analysis on Concept and Practice of Implementation of Kindergarten Multicultural Curriculum
}

\author{
Han Zhang \\ College of Preschool Education Research, Shandong Yingcai University, Ji'nan, 250101, China
}

Keywords: Kindergarten education. Course diversification. Concept. Key points of practice

\begin{abstract}
Under the background of constant increase of talent competition pressure, multicultural curriculum is an inevitable trend of kindergarten curriculum setting as well as a necessary way for self-development of kindergarten teachers. The concept of implementation of multicultural curriculum is a reasonable guidance over curriculum construction as well as planning of the direction of curriculum construction practice. Infants are pillars of the future development of China. Kindergarten educational curriculum is the guarantee of improving abilities of infants and allowing them to realize diversified development. This paper briefly describes the significance of implementing diversified curriculum based on this situation, analyzes the concept of multicultural curriculum construction, puts forward several practical methods on this basis and aims at optimizing kindergarten curriculum construction and improving the level of early childhood education in China.
\end{abstract}

\section{Introduction}

Multiculture is an important theme of the survival and development of people as well as basic guarantee of integrated development of infants. The diversification of Chinese social and historical development has laid a diversified foundation for the development of education. In kindergarten education, the implementation of multicultural curriculum is a good wish for joint development of education, infants and society. Therefore, it is also an inevitable trend of educational development. In terms of the setting of kindergarten curriculum, China has been constantly using foreign advanced educational thoughts for reference and integrating the diversification of culture into educational contents that can be accepted by infants. The implementation of diversified curriculum will be inevitably accompanied by fluctuations of curriculum view, value, view on children, cultural accumulation and educational concept. Each concept need to realize the final pursuit for educational purpose in constant integration and show the vision and rational understanding of infant education course.

\section{Concept of kindergarten multicultural curriculum}

\section{Concept of curriculum implementation subject}

In the educational world, traditional exam-oriented education has been gradually eliminated and replaced by quality-oriented education. Currently, same as elementary and secondary education, infant education needs to take educational object as classroom body and actually realize humanistic education. Education is an activity with strong practicalness. In curriculum design, it is required to implement human culture. Infants are in the primary development stage in life. Their education belongs to the stage of making them "become human". In this process, it is necessary to pay attention to the training of consciousness and education demand. Curriculum design should pay attention to the training of right and wrong ideas and value judgment of infants and meanwhile pay attention to development and respect. Specifically speaking, its concept includes the following aspects:

\section{Cultural production subject}

Curriculum education belongs to a method and approach for the implementation of cultural education. It is a periodic process of cultural friction, crash and integration of old and new cultures as well as a dynamic process. Cultural production belongs to an essential character of kindergarten curriculum. Infants have immature thinking. The implantation of culture to them is mostly 
self-created rather than subject to despotism. When implementing multicultural curriculum, kindergartens should understand that this is an innovative process of optimizing the relationship between infants and teachers and regard multiculture as new function of education.

\section{Specify objectives of curriculum implementation}

Objectives of curriculum implementation belong to a process of individualization, materialization and psychologization of curriculum. Optimal educational objectives in the near term should be determined according to individual differences of educational objects in kindergartens. Environment has great influence on infant education. Educational concept should ensure the interaction between infants and environment and allow them to develop constantly with the interaction with surrounding environment. Under the background of constant development of era concept, teachers' concepts in education, children and curriculum have been updated correspondingly and make them not produce adverse influence on the creation of diversified curriculum. Educational concept should guarantee the smooth implementation of objectives and real needs of infant development.

\section{Optimize evaluation method}

Though academic pressure in kindergartens is less than that in high school stage, teachers should establish a scientific and reasonable evaluation method and conduct evaluation from multiculture. Evaluation is a main content in education as well as the theoretical foundation and guarantee of curriculum development. Curriculum evaluation should be a result of joint participation of teachers, parents and infants. The difference of each subject represents the difference of their standpoint. It is required to respect opinions or suggestions of each subject on the basis of multiculture, reduce negative factors as far as possible in the evaluation and make evaluation become the guarantee impelling the diversification of educational culture. Multicultural curriculum in kindergartens is the primary educational stage of infants. It is required to not only strengthen the care and multilayer teaching for infants, but also reduce the limitation of the post of teachers from multiple perspectives and understand existing problems of the evaluation standard as a spectator. Only in this way can educational level and infant development be improved.

\section{Ecological curriculum concept}

\section{Ecological features of curriculum objectives}

This stage mainly refers to the respect to the environment. Infants are required to respect and protect the environment and live in harmony with nature. Under the guidance of this concept, teachers can move the educational classroom outdoors and allow infants to feel the charm of nature in person and improve their aesthetic idea and quality training by perceiving and exploring nature. For example, teachers can ask infants to observe honey gathering of little bees and learn the diligence of bees; or observe the growth of grass in rock tunnels and learn the tenacity of grass. Ecological educational thought requires integrating natural culture into education and helping infants to integrate themselves into the natural world.

\section{Ecological features of curriculum content}

Under ecological concept, educational contents set up by teachers should start from life reality, make infants understand the influence of leaves, kernels and grit in the natural environment on the natural world, reduce the discard of sundries such as paper box, zip-top can and plastic bottle and help infants set up the concept of protecting nature.

\section{Objective education concept}

A specific objective should be set for the development of anything. For infant education, the objective of its diversified curriculum is to enrich the view of infants and make them have experience and ideological and moral qualities required for growth. Infants are in the primary development stage. The level of their thinking determines that education must take diversification route so as to ensure the effectiveness of education. The final objective of infant education is to make infants become human rather than human that teachers want them to be. Teachers should ensure the construction of objectives of educational concept and allow infants to optimize and fully exert their combination of intelligence under multicultural education.

Psychologists think that each individual has 9 different aptitudes. The exertion of aptitude and deviation of educational direction will influence the future development direction of infants. 
Kindergarten teachers should pay attention to the training of differences of infants, attach importance to the value and emotional education of each person, make infants' thinking more developmental and diversified and make them understand the world better through differences of the angle of view for the world and obtain diversified feelings and cultural experience.

\section{Key points in practice of kindergarten multicultural curriculum}

\section{Optimize textbook compilation and improve educational quality}

Educational curriculum textbook is an important curriculum resource of kindergarten education which has direct influence on curriculum effectiveness. The composition and content of compilation are basic guarantee of textbook effectiveness. To ensure the smooth implementation of multicultural curriculum, it is required to conduct the compilation work of textbook well. In textbook compilation, it is required to first guarantee a textbook compilation team composed of professionals such as kindergarten education teachers with experience, infant education psychology researchers and children education experts. Teachers play an important role. Kindergarten teachers go deep into the front line and directly contact with infants and master infants' psychological characteristics and acceptance capability more specifically.

To realize multiculture of education, it is required to ensure that multiculture has been integrated into textbook to the extent that can be accepted by infants in textbook compilation. Attention should be paid to the following in terms of the content of textbook compilation: first, educational content; second, educational difficulty. Only in this way can multiculture be actually integrated in kindergarten education and various concepts of kindergarten education be implemented.

\section{Pay attention to traditional culture and inherit national features}

When each level of the society is filled with modern culture, educational contents received by infants are covered by modern culture. They have little understanding of traditional culture. As cultural contents that infants can receive rapidly are mostly contents that they often touch at ordinary times, the acceptance level of traditional culture is low and they have little impression on contents not appearing in their life circle frequently.

Traditional culture emphasized in this paper mainly consists in excellent literary works in ancient China such as four great inventions and moral stories and excellent morality inherited for thousands of years in China. On the one hand, it is required to strengthen infants' impression on traditional good things such as excellent artwork and literary works in education, make them proud of the traditional culture of China and train their national honor through all this. On the other hand, education should pay attention to the training of infants' psychological quality and morality, such as "respect the old and cherish the young" and "be diligent and hardworking". Infant stage is the primary stage of growth of human beings as well as the stage that their ideological value is most easily influenced. In this stage, infants' world outlook, outlook on life and value are most easily educated. Therefore, kindergarten education should use this stage well to allow infants to master the essence of Chinese traditional moral culture and lay a foundation for the training of their correct views.

Meanwhile, multiculture should also contain Chinese rural culture. Currently, some educational institutions consider that we should no longer classify rural culture into infant education. However, these cultures are the crystal of wisdom of laboring people in essence. Relative to popular online games and video games currently, rural culture can improve the operational ability of infants. In addition, for some folk cultures and songs and dances, teachers can make infants understand the charm of these cultures and inherit and promote them in the form of video or imitation.

In infant education curriculum, the diversification of culture is manifested in different aspects. Teachers should pay attention to the allocation of these education contents in the educational process at ordinary times and not only carry out implementation in allusion to modern culture and make infants understand characteristic cultures in the world, but also pay attention to publicize Chinese traditional culture and make the essence of Chinese traditional culture handed down. Kindergarten education should keep up with the development of the era and actually improve the quality of infant curriculum. 


\section{Pay attention to local culture and explore cultural characteristics}

Cultural diversification at this level is similar to the inheritance of traditional culture. It is necessary to explore and inherit local culture. Cultural inheritance is not blind spread. Instead, it is required to make infants understand the spirit implied by local culture on the original basis. A famous educator said, "the mode of life of a person is greatly influenced by his living environment. Therefore, multicultural education should start with infant stage, present the essence of local culture in front of infants and influence the living habit of infants.

For infants, their growth environment severely influences their impression on the city where they live. For example, the life experience of infants living in Sichuan and Chongqing is mostly spicy hot pot, enthusiastic mountain city and influence of red culture. The life experience of infants living in northeast regions is mostly central heating and the happiness of severe winter and cold snow. The former makes characters of infants tend to be uprightness and enthusiasm and the latter makes characters of infants tend to be tenaciousness and generosity. The main objective of geo-relation cultural exploration is to make infants produce a cordial feeling and sense of pride through the feeling about geographic position and promote the improvement of acceptance effect of multiculture. Therefore, teachers should pay more attention to in-depth exploration of local region in education, especially cultural characteristics little left, such as wharf culture, Chongqing culture and hot pot culture. Meanwhile, existing landscapes different from high buildings and large mansions in China should also be integrated into education, such as the city of fog and mountain city and stilted building. Local culture should be used to realize cultural diversification of infant education.

\section{Integrate world cultures and expand the horizon of infants}

Though infants are in the primary stage of receiving education, cultural diversification is a content existing objectively. Therefore, world cultures can be integrated in infant stage. In terms of curriculum design, it is necessary to impart world cultures to a certain extent on the basis of local culture. Connection with the world is the trend of future education. We cannot restrain the horizon of infants due to cocoon-type education. Therefore, it is required to strengthen the communication between infants and world cultures actively, integrate cultures of other countries with Chinese culture positively and make infants accept beneficial cultural components in terms of education curriculum design.

In addition, cultural integration should not only pay attention to the introduction of culture of developed countries, but also give consideration to countries in Africa and Australia etc. and actually realize diversified cultural education. Infants are future pillars of the development of China. Therefore, it is required to look around, realize cultural integration consciously through the absorption of culture in multiple angles and lay a foundation for the implantation of diversified culture in the future.

\section{Conclusion}

Currently, kindergarten teachers' understanding of multicultural curriculum is still in the primary stage and is vague. Therefore, complete educational objectives and contents cannot be established. Teachers should strengthen the learning in this aspect, expand the horizon of infants on the basis of strengthening national education and make them touch the culture in other regions of China or other countries. Meanwhile, it is necessary to implement multiculture in kindergarten curriculum design, start from the compilation of textbook and use existing teaching resources to actually present multiculture in front of infants, make infants in an individualized, life-like and integrated educational system and actually realize multi-angle development of infant educational culture.

\section{Acknowledgments}

This paper is a phased achievement of rolling subject of Chinese preschool education seminar during the 12th Five-year Plan: "Research on Inheritance of Intangible Cultural Heritage in Infant Education - Take Shandong Province for Example” (project number: 201310-SD-10). 


\section{References}

[1] Zhao Haiyan, Yang Xiaoping: Concept of Implementation of Kindergarten Multicultural Curriculum, Social Scientist, 2013(08).

[2] Sun Yajuan: Discussions on Establishment of Kindergarten Multicultural Curriculum - Take Kindergartens in Regions Inhabited by Ethnic Groups in China for Example, Journal of Educational Development (second half of the month), 2010(07).

[3] Zhao Haiyan: View on Value Orientation of Implementation of Kindergarten Multicultural Curriculum from Traditional Philosophy, School Party Building and Ideological Education, 2013(05).

[4] Ma You: How to Design Multicultural Curriculum, Journal of Inner Mongolia Normal University (Educational Science Edition), 2008(03).

[5] Jin Shumei, Li Jin: Analysis on Concept, Objectives and Implementation Ways of Multicultural Curriculum, Journal of Jingdezhen Comprehensive College, 2011(02).

[6] Jin Shumei: Inspirations of Implementation Ways of Multicultural Curriculum on Three-grade Curriculum Management System, Jilin Education, 2011(02). 